\title{
Relationship between depressive symptoms and acute low back pain at first medical consultation, three and six weeks of primary care
}

\section{Achim Elfering, Anja Käser \& Markus Melloh}

To cite this article: Achim Elfering, Anja Käser \& Markus Melloh (2014) Relationship between depressive symptoms and acute low back pain at first medical consultation, three and six weeks of primary care, Psychology, Health \& Medicine, 19:2, 235-246, DOI: 10.1080/13548506.2013.780131

To link to this article: https://doi.org/10.1080/13548506.2013.780131

曲 Published online: 20 Mar 2013.

Submit your article to this journal $₫$

Џll Article views: 191

Q View related articles $₫$

View Crossmark data $\nearrow$

Citing articles: 7 View citing articles 


\title{
Relationship between depressive symptoms and acute low back pain at first medical consultation, three and six weeks of primary care
}

\author{
Achim Elfering $^{\mathrm{a} *}$, Anja Käser ${ }^{\mathrm{a}}$ and Markus Melloh ${ }^{\mathrm{b}}$ \\ ${ }^{a}$ Department of Psychology, University of Bern, Bern, Switzerland; ${ }^{b}$ Western Australian Institute \\ for Medical Research, University of Western Australia, Nedlands, Australia
}

(Received 7 November 2012; final version received 21 February 2013)

\begin{abstract}
Background: Aim of the study was to test lagged reciprocal effects of depressive symptoms and acute low back pain (LBP) across the first weeks of primary care. Methods: In a prospective inception cohort study, 221 primary care patients with acute or subacute LBP were assessed at the time of initial consultation and then followed up at three and six weeks. Key measures were depressive symptoms (modified Zung Self-Rating Depression Scale) and LBP (sensory pain, present pain index and visual analogue scale of the Short-Form McGill Pain Questionnaire). Results: When only cross-lagged effects of six weeks were tested, a reciprocal positive relationship between LBP and depressive symptoms was shown in a cross-lagged structural equation model $(\beta=.15$ and $.17, p<.01)$. When lagged reciprocal paths at three- and sixweek follow-up were tested, depressive symptoms at the time of consultation predicted higher LBP severity after three weeks $(\beta=.23, p<.01)$. LBP after three weeks had in turn a positive cross-lagged effect on depression after six weeks $(\beta=.27$, $p<.001)$. Conclusions: Reciprocal effects of depressive symptoms and LBP seem to depend on time under medical treatment. Health practitioners should screen for and treat depressive symptoms at the first consultation to improve the LBP treatment.
\end{abstract}

Keywords: prospective study; acute low back pain; depression; prognosis

\section{Introduction}

Depression and chronic pain including low back pain (LBP) are among the most common diseases that health practitioners encounter today (Bair, Robinson, Katon, \& Kroenke, 2003; Polatin, Kinney, Gatchel, Lillo, \& Mayer, 1993). They are both related to each other (Fishbain, Cutler, Rosomoff, \& Rosomoff, 1997; Melloh et al., 2009); however, their relationship has not yet been fully explored. Polatin et al. (1993) found that depression is a common diagnosis in patients with chronic LBP. Currie and Wang (2004) found in a cross-sectional analysis that LBP is a strong predictor of major depression. Moreover, a recent study showed that depression is most strongly related to LBP compared with other diseases (Shaw et al., 2010). Two dominant models have been used to explain the association between depression and LBP.

\section{Antecedent, consequence and reciprocal model}

The antecedent model proposed that depression is responsible for the development and maintenance of chronic pain (Fishbain et al., 1997). The antecedent model can be traced

*Corresponding author. Email: achim.elfering@psy.unibe.ch 
back to findings that a high level of depression weakens the ability to deal with the current LBP problem (Von Korff \& Simon, 1996). Studies in primary care settings showed that baseline depressive symptoms predicted LBP at three (Young Casey, Greenberg, Nicassio, Harpin, \& Hubbard, 2008), six (Melloh et al., 2011), ten (Potter \& Jones, 1992), and twelve months (Cherkin, Deyo, Street, \& Barlow, 1996; Linton et al., 2011) and even at eight years (Magni, Moreschi, Rigatti-Luchini, \& Merskey, 1994).

On the other hand, the consequence model implies that LBP elicits or increases depressive symptoms (Fishbain et al., 1997) as a reaction to the challenges of current pain experiences. This model is in line with Seligman's concept of learned helplessness (Seligman, 1975). According to this theory, high pain severity can be interpreted as a negative and uncontrollable event resulting in learned helplessness. In agreement with this, studies demonstrated that a higher pain severity at baseline is associated with increase in depressive symptoms (Bair et al., 2003; Magni et al., 1994; Von Korff, Ormel, Katon, \& Lin, 1992).

The antecedent and consequence hypotheses both apply when the true relation between depressive symptoms and LBP across time is reciprocal. Polatin et al. (1993) showed that $55 \%$ of depressive pain patients were depressed before the onset of a chronic LBP episode and 45\% developed depressive symptoms after having chronic LBP. In a sample of acute back, hip, or knee pain patients, Kroenke et al. (2011) found a longitudinal reciprocal relationship between pain and depressive symptoms. In accordance, Hurwitz, Morgenstern and Yu (2003) reported that LBP and psychological distress were antecedent and consequence of each other. The purpose of this study was to model the longitudinal relationship of LBP and depressive symptoms in patients with acute or sub-acute LBP. Based on the reciprocal model assumptions, the hypothesis of this longitudinal study is that depressive symptoms and LBP are risk factors across time for each other in the mid-term (six weeks) and even in the short-term (three weeks).

\section{Methods \\ Participants}

Participants suffering from LBP in primary care and coming in for their first consultation were recruited consecutively across New Zealand from April 2008 until October 2010 (Melloh et al., 2008; Melloh, Elfering, Chapple et al., 2012; Melloh, Elfering, Salathe et al., 2012). During the consultation, LBP patients decided whether they wished to participate in the study. After receiving initial verbal consent, the health practitioners provided the participants with written information about the study. Within the following week, the patients were screened by a structured telephone interview conducted by a research nurse. To be eligible, the participants had to have a first episode of acute or sub-acute LBP, between 18 and 65 years old, to be able to read and write in English and give written consent. Exclusion criteria were to be defined as chronic LBP (longer than 12 weeks of LBP by the time of the first visit of the practitioner), specific LBP (for example, tumour, infection, osteoporosis, ankylosing spondylitis, fracture, deformity, inflammatory process, cauda equina syndrome), severe comorbidity (for example, disabling osteoarthritis of the hip or knee joint), pregnancy, unavailability to complete the questionnaire, and the absence of LBP at the time of screening. When participants satisfied the inclusion criteria, the baseline questionnaire was forwarded by mail and participants were asked to return it within one week. The data were collected in three ways: the baseline assessment (T0) was followed by two follow-up assessments after three (T1) and six weeks (T2). At each time point, a reminder was sent after one and two 
weeks if the questionnaire was not returned. Upon completion of each assessment, a gift voucher of 10 New Zealand dollars (grocery, fuel, or book voucher) was provided.

The initial sample consisted of 562 participants who were consecutively screened after consultation. Of these individuals, 124 were found to be ineligible; 10 were LBPfree at the time of the screening interview, 93 had chronic LBP, eight were diagnosed with specific LBP, two had osteoarthritis of the hip or knee joint, three were pregnant, two were not available for follow-ups, and six were older than 65 years. In addition, 26 patients decided not to participate, and 97 did not return the baseline questionnaire. At baseline, 315 participants were enrolled. In the follow-up assessments, 256 patients participated at T1 and 224 at T2. Thus, the final longitudinal sample size of 221 provides sufficient statistical power in structural equation modelling (SEM) (Barrett, 2007). The sample consisted of majority $(64.7 \%)$ women with a mean age of 35.6 years $(\mathrm{SD}=12.8)$.

\section{Self-report measures}

The questionnaires used in this study are based on the Multinational Musculoskeletal Inception Cohort Study Statement (Pincus, Santos, Breen, Burton, \& Underwood, 2008). To improve the quality of assessments in LBP populations, the statement recommends a core set measures. Among others, these measures include pain and also mental well-being.

Depressive symptoms were assessed with the modified Zung Self-Rating Depression Scale of the Distress and Risk Assessment Method (Main, Wood, Hollis, Spanswick, \& Waddell, 1992; Zung, 1965). The scale is a 23-item questionnaire. Items values range from rarely or none of the time (1) to most of the time (4). An example of an item is: "How have you been feeling recently: I feel downhearted and sad". The scale is reported to have acceptable reliability and validity (Main et al., 1992).

LBP was measured by the Short-Form McGill Pain Questionnaire (SF-MPQ, Melzack, 1987). The SF-MPQ included a Pain Rating Index (PRI), consisting of 15 adjectives of two subscales describing pain in last week as "sensory" (S-PRI with eleven items) and "affective" (A-PRI with four items). Examples of adjectives were "sharp" or "shooting" for the sensory subscale. Each item was rated on a four-point Likert scale ranging from none (0) to severe (3). Moreover, the SF-MPQ included a Visual Analogue Scale (VAS) asking for LBP in last week. The VAS assessed the pain intensity on a $10 \mathrm{~cm}$ horizontal line, ranging from no pain (left) to worst possible pain (right). Finally, the SF-MPQ included the Present Pain Index (PPI). The PPI measures the present pain intensity on a six-point Likert scale. It was anchored in no pain (0) and excruciating pain (5). Sensitivity to change (Melzack \& Katz, 2006), reliability and validity (Burckhardt \& Bjelle, 1994; Georgoudis, Watson, \& Oldham, 2000) of the SFMPQ have been demonstrated. The sub-scale A-PRI with four "affective pain" items was excluded from analysis due to the possibility of criterion contamination (content overlap) with the Zung Self-Rating Depression Scale (Pincus \& Williams, 1999).

\section{Study design}

The present work is a longitudinal three-wave panel design in which each assessment was conducted with the same sample and instruments. The time lag of three weeks is in line with studies showing the most rapid improvements of acute LBP to occur within one month (Andersson, 1999; Pengel, Herbert, Maher, \& Refshauge, 2003). The study was performed according to the recommendations of the Declaration of Helsinki (2008) 
and has been approved by the local Lower South Regional Ethics Committee of New Zealand (LRS/08/03/008).

\section{Statistical analyses}

The data analysis was conducted with statistical package for the social sciences (SPSS) 18 and SPSS Amos 18 (analysis of moment structures). As the hypothesis was directional, alpha was set to .05 , one-tailed.

Measurement models were conducted to define latent variables. Subscales (pain) and item parcels (depressive symptoms), respectively, were used as indicators. Measurement models were estimated with free loadings between latent constructs and constraint loadings for equivalent paths at different point in time (Model 1 and Model 2). All constructs were allowed to correlate with one another and the same indicators were correlated across time (Cole \& Maxwell, 2003). Then LBP and depressive symptoms were cross-sectionally correlated and tested in crosslagged structural models (Cole \& Maxwell, 2003). Age, gender and BMI were introduced into the structural models as control variables because they are related to LBP and depressive symptoms (Dragan \& Akhtar-Danesh, 2007; Elfering \& Mannion, 2008; Hirschfeld \& Weissman, 2002). The first cross-lagged model only included six-week-cross-lagged paths from time 0 to time 2 (Model 3). The second cross-lagged model only included three-week-cross-lagged paths (Model 4) and the third cross-lagged full model included three-week and six-week-cross-lagged paths (Model 5). Short-term medication for acute lower back pain may help slow or prevent increases in depressive symptoms (Chou \& Hoyt Huffman, 2007). Hence, multi-group analysis tested whether results for full Model 5 differed for those patients who received pain medication compared with those who did not. As medication was assessed retroactively after six months only, the sample for this analysis consisted of 75 participants who received pain medication (coded "1") and 72 participants who did not (coded " 0 "). After six months, 74 participants had been lost to follow-up. A model with freely estimated parameters between groups (Model 6) was compared with a model in which specific structural paths (from pain to depression and vice versa) were constrained to be the same in both groups (Model 7). If Model 6 fits the data significantly better than Model 7, the groups differed significantly. In a next step, each path loading from pain to depressive and vice versa was tested to differ between patients with and without pain medication.

\section{Results}

\section{Descriptives and intercorrelations}

The sample characteristics are displayed in Table 1. There were no significant differences in demographics, LBP history, LBP severity and depressive symptoms between the study sample and participants who were lost to follow-up.

The stabilities of indicators of LBP ( $r$ between .44 and .69 , all $p<.001)$ and depression ( $r$ between .65 and .70 , all $p<.001$ ) were high. The inter-correlations between LBP indicators and depressive symptoms at the same time and across time were all positive and significant ( $r$ between .21 and .60 , all $p<.01$ ). Among the control variables, age was associated with higher depressive symptoms at $\mathrm{T} 1(r=-.16, p<.05)$ and 
Table 1. Baseline characteristics of participants who completed 12-week follow-up vs. participants lost to follow-up.

\begin{tabular}{|c|c|c|c|c|}
\hline & Variables & $\begin{array}{l}\text { Participants } \\
(n=221)\end{array}$ & $\begin{array}{l}\text { Lost to } \\
\text { follow-up } \\
(n=94)\end{array}$ & $p$ \\
\hline Current LBP & $\begin{array}{l}\text { Duration episode of LBP (days) } \\
\text { (mean[SD]) }\end{array}$ & $20.2(15.1)$ & $23.0(15.6)$ & $.140^{\mathrm{a}}$ \\
\hline \multirow{6}{*}{$\begin{array}{l}\text { Lifestyle factors } \\
\qquad(n[\%])\end{array}$} & \multicolumn{3}{|l|}{ Physical activity (IPAQ score) } & $.576^{\mathrm{a}}$ \\
\hline & - Low & $29(13.4 \%)$ & $10(10.9 \%)$ & \\
\hline & - Moderate & $126(58.1 \%)$ & $54(58.7 \%)$ & \\
\hline & - High & $62(28.6 \%)$ & $28(30.4 \%)$ & \\
\hline & Smoking status & $94(42.5 \%)$ & $38(40.4 \%)$ & $.730^{\mathrm{b}}$ \\
\hline & $\begin{array}{l}\text { Increased alcohol consumption } \\
\text { (Audit-C) }\end{array}$ & $91(41.2 \%)$ & $47(50 \%)$ & $.150^{\mathrm{b}}$ \\
\hline $\begin{array}{l}\text { Marital status } \\
\quad(n[\%])\end{array}$ & In a relationship/married & $97(43.9 \%)$ & $39(42.4 \%)$ & $.734^{\mathrm{b}}$ \\
\hline Education & No formal schooling & $1(.5 \%)$ & $1(1.1 \%)$ & $.540^{\mathrm{a}}$ \\
\hline Status & $<$ Primary school & $3(1.4 \%)$ & $1(1.1 \%)$ & \\
\hline \multirow[t]{5}{*}{$(n[\%])$} & Primary school & $12(5.4 \%)$ & $5(5.3 \%)$ & \\
\hline & Secondary school & $36(16.3 \%)$ & $10(10.6 \%)$ & \\
\hline & High school & $60(27.1 \%)$ & $36(38.3 \%)$ & \\
\hline & College/university & $86(38.9 \%)$ & $32(24 \%)$ & \\
\hline & Postgraduate degree & $23(10.4 \%)$ & $9(9.6 \%)$ & \\
\hline \multirow{3}{*}{$\begin{array}{l}\text { Pain (mean } \\
\text { [SD]) }\end{array}$} & S-PRI & $28.2(18.5)$ & $26.8(15.5)$ & $.516^{\mathrm{a}}$ \\
\hline & VAS & $37.1(23.3)$ & $36.9(24.2)$ & $.932^{\mathrm{a}}$ \\
\hline & PPI & $31.0(18.9)$ & $28.9(18.2)$ & $.362^{\mathrm{a}}$ \\
\hline $\begin{array}{l}\text { Depressive } \\
\text { symptoms } \\
\text { (mean[SD]) }\end{array}$ & Zung & $21.9(11.5)$ & $23.2(11.4)$ & $.361^{\mathrm{a}}$ \\
\hline \multirow[t]{3}{*}{ Pain medication } & Yes $[\%]$ & $75(33.9 \%)$ & n.a. & n.a. \\
\hline & No $[\%]$ & $72(32.6 \%)$ & n.a. & n.a. \\
\hline & No information/missing $(n[\%])$ & $74(33.5 \%)$ & & \\
\hline \multirow[t]{12}{*}{ Demographics } & Age $(\operatorname{mean}[\mathrm{SD}])$ & $35.6(12.9)$ & $33.0(11.8)$ & $.096^{\mathrm{a}}$ \\
\hline & BMI (mean[SD]) & $28.0(6.3)$ & $27.0(5.9)$ & $.229^{\mathrm{a}}$ \\
\hline & Female $(n[\%])$ & $143(64.7 \%)$ & $66(70.2 \%)$ & $.346^{\mathrm{b}}$ \\
\hline & Ethnicity $(n[\%])$ & & & $.911^{\mathrm{b}}$ \\
\hline & - NZ European & $164(74.2 \%)$ & $69(74.2 \%)$ & \\
\hline & - Maori & $8(3.6 \%)$ & $3(3.2 \%)$ & \\
\hline & - Samoan & $2(0.9 \%)$ & $1(1.1 \%)$ & \\
\hline & - Chinese & $2(.9 \%)$ & $2(2.2 \%)$ & \\
\hline & - Indian & $3(1.4 \%)$ & $2(2.2 \%)$ & \\
\hline & - Other & $28(12.7 \%)$ & $10(10.8 \%)$ & \\
\hline & - Maori/NZ European & $12(5.4 \%)$ & $6(6.5 \%)$ & \\
\hline & - NZ European/Maori & $2(.9 \%)$ & $0(.0 \%)$ & \\
\hline
\end{tabular}

Notes: Figures are numbers (percentages) or means (standard deviation) of participants. IPAQ=international physical activity questionnaire; Audit- $\mathrm{C}=$ alcohol use disorders identification test - alcohol consumption questions; $\mathrm{S}-\mathrm{PRI}=\mathrm{SF}-\mathrm{MPQ}$ sensory pain scale; $\mathrm{VAS}=$ visual analogue scale; $\mathrm{PPI}=$ present pain index.

${ }^{\mathrm{a}}$-test.

${ }^{\mathrm{b}} \chi^{2}$ test.

$\mathrm{T} 2(r=-.14, p<.05)$ and pain values at T0 $(r=-.14, p<.05)$. Being a woman was associated with higher depressive symptoms at T0, T1, and T2 $(r$ between .14 and .30 , $p<.05)$ but not with higher pain values. BMI was positively related with depressive symptoms at T0, T1, and T2 ( $r$ between .19 and .31 , all $p<.05)$ and pain at T0, T1, and T2 ( $r$ between .15 and .26, all $p<.05)$. 


\section{Measurement models}

As stated in the methods, before testing the study hypothesis, a measurement model was conducted. A model with freely estimated parameters (Model 1) and a constrained model (Model 2) were compared. Model 2 assumed same loadings of indicators on latent variables at T0, T1, and T2 (metric invariance). Both models were resulted in a good fit (Table 2). Due to the non-significant $\chi^{2}$ difference test $(p=.139)$, the more stringent constrained model was favoured and the constraints on factor loadings were retained in cross-lagged models.

\section{Cross-lagged models}

In the six-week time lag model (Model 3), a reciprocal relationship between LBP-severity and depressive symptoms with significant path coefficients from depressive symptoms T0 to pain T2 $(\beta=.17, p<.01)$ and from pain T0 to depressive symptoms T2 $(\beta=.15$, $p<.01$ ) was found (Figure 1). The three-week lag model (Model 4, Figure 2) showed time-specific significant paths: depressive symptoms at T0 predicted pain at T1 $(\beta=.23$, $p<.01)$ and pain at T1 predicted depressive symptoms at T2 $(\beta=.26, p<.001)$. Moreover, the model fit was significantly better in the three-week time lag model than in the six-week time lag model $\left(\chi_{\text {diff }}^{2}(4)=19.21, p<.01\right)$. When three- and six-week lagged paths were tested simultaneously in a full model (Model 5), the time-specific two paths that were significant in Model 4 remained unchanged, while the six-week lagged paths

Table 2. Structural equation models of the relationship between depressive symptoms and acute low back pain.

\begin{tabular}{|c|c|c|c|c|c|c|c|c|}
\hline Model & $\chi^{2}$ & df & $\chi_{\text {diff }}^{2}$ & $\mathrm{df}_{\text {diff }}$ & CFI & TLI & RMSEA & $\begin{array}{l}\text { 90\% CI of } \\
\text { RMSEA }\end{array}$ \\
\hline \multicolumn{9}{|l|}{ Measurement models } \\
\hline 1 Free loadings & 207.59 & 192 & & & .995 & .993 & .019 & $.000-.036$ \\
\hline $\begin{array}{l}2 \text { Measurement } \\
\text { invariance }\end{array}$ & 221.03 & 202 & & & .994 & .992 & .021 & $.000-.037$ \\
\hline Model 1 vs. 2 & & & 13.44 & 10 & & & & \\
\hline Cross-lagged models & & & & & & & & \\
\hline $\begin{array}{l}3 \text { 6-week time lag } \\
\text { Model } 3 \text { vs. } 4\end{array}$ & $218.96^{* * *}$ & 152 & $19.21^{* *}$ & 4 & .977 & .968 & .045 & $.030-.057$ \\
\hline $\begin{array}{l}4 \text {-week time lag } \\
\text { Model } 4 \text { vs. } 5\end{array}$ & $199.75^{* *}$ & 150 & .72 & 2 & .983 & .976 & .039 & $.023-.052$ \\
\hline $5 \quad$ Full model & $199.03^{* *}$ & 148 & & & .983 & .975 & .040 & $.024-.053$ \\
\hline \multicolumn{9}{|l|}{ Multi-group analysis } \\
\hline 6 Free loadings & $390.61^{* * *}$ & 300 & & & .955 & .936 & .046 & $.032-.058$ \\
\hline $\begin{array}{l}7 \text { Pain T0 - depressive } \\
\text { symptoms T1 }\end{array}$ & $396.13^{* * *}$ & 301 & & & .952 & .933 & .047 & $.033-.059$ \\
\hline Model 6 vs. 7 & & & $5.521^{*}$ & 1 & & & & \\
\hline
\end{tabular}

Notes: $\mathrm{df}=$ degrees of freedom; $\chi_{\text {diff }}^{2}=\chi^{2}$ difference test; $\mathrm{CFI}=$ comparative fit index; TLI $=$ Tucker-Lewis index; RMSEA = root-mean-square error of approximation; $\mathrm{CI}=$ confidence interval. Acceptable values for the fit indices of CFI and TLI $>.95$ and RMSEA $<.06$. The $\chi^{2}$ diff test was used to statistically compare the fit of the models. A non-significant $\chi_{\text {diff }}^{2}$ test indicated that the models fit the data equally and the more parsimonious model could be favoured.

${ }^{*} p<.05$.

${ }_{* *}^{* *} p<.01$.

${ }^{* * *} p<.001$. 


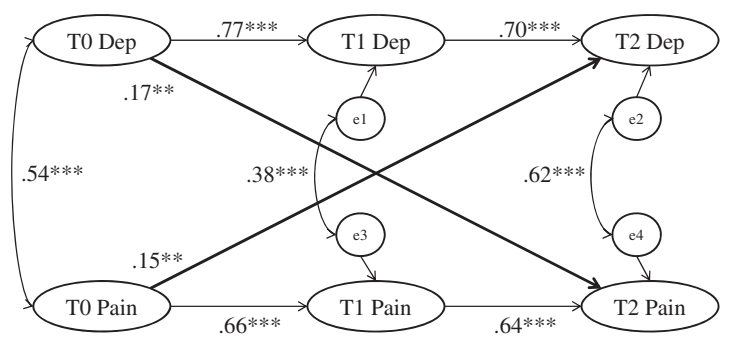

Figure 1. Model 3: Cross-lagged relationships between depressive symptoms and pain with a time lag of six weeks.

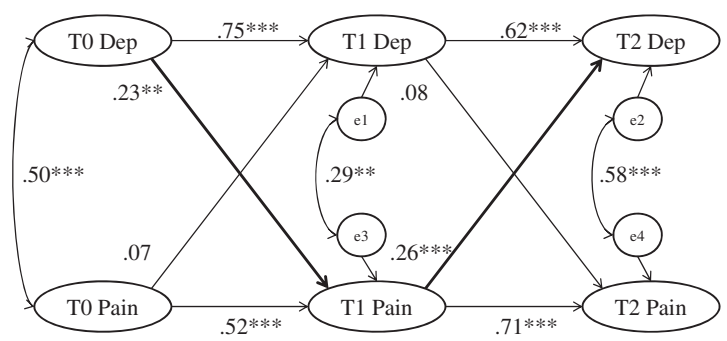

Figure 2. Model 4: Cross-lagged relationships between depressive symptoms and pain with a time lag of three weeks.

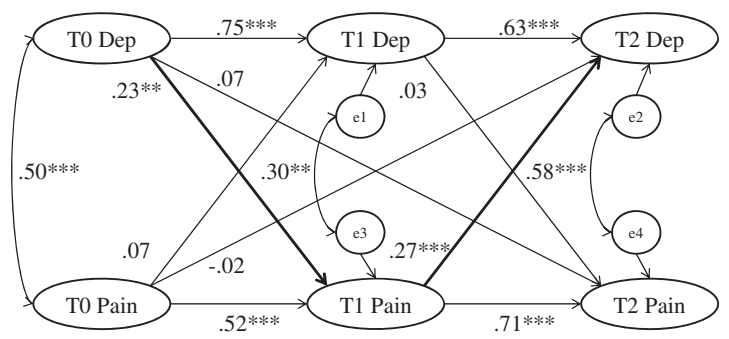

Figure 3. Model 5: Full cross-lagged relationships between depressive symptoms and pain.

from Model 3 became insignificant (Figure 3). The full Model 5 showed no improvement in model fit compared with the three-week time lag Model $4\left(\chi_{\text {diff }}^{2}(2)=.72, n s\right)$.

\section{Comparison of patients with and without pain medication}

Model 6, in which all path coefficients were allowed to be freely estimated in the medication and non-medication group, was compared with Model 7 in which paths between pain and depressive symptoms were constrained to be the same in both groups. Comparison of fit indices indicated the superiority of Model 6 compared with Model 7. To locate the source of deviating model fit, each path from pain to depressive symptoms and vice versa was tested to differ between groups. For patients without pain medication, the path from pain T0 to depressive symptoms T1 was positive and significant $(\beta=.31, p<.01)$, whereas in patients receiving medication, the path was negative and non-significant $(\beta=-.13, n s)$. 


\section{Discussion}

Time-specific reciprocal cross-lagged paths between depressive symptoms and LBPseverity were found, although depressive symptoms and LBP-severity showed considerable stability and cross-sectional relations were controlled. Short-term effects with a lag of three weeks showed only depressive symptoms at consultation predicted pain after three weeks and the latter in turn predicted subsequent depressive symptoms at six weeks. From that, two main conclusions can be drawn. Firstly, the mutual dependence of depressive symptoms and LBP-severity could be treatment-time-specific. The major adverse effects of depressive symptoms on LBP-severity may take place in first three weeks of medical treatment. In the longer run, these impacts occur too, but disappear when controlled for short-term effects. Persisting levels of LBP after three weeks increase the risk of higher depressive symptoms after six weeks of treatment.

Secondly, we conclude that it is not possible to clarify time-specific antecedent and consequence relations when time periods between follow-ups are six weeks. In this situation, presumably reciprocal relations are found like in Model 3 (for example, Angst, Verra, Lehmann, Aeschlimann, \& Angst, 2008). A recent analysis of acute LBP recovery showed that average reduction of pain is $50 \%$ in the first six weeks (Menezes Costa et al., 2012). Thus, the future study of directional antecedent and consequence assumptions should apply measurements on week level (Elfering, Mannion, Jacobshagen, Tamcan, \& Müller, 2009).

Some preliminary considerations regarding the temporal relationships can be drawn. The results showed a tendency that the modes of action change in the course of treatment time. At the time patients seek care, depressive symptoms were a risk factor for increased LBP after three weeks because they may have resulted in a decreased capacity to cope with LBP (for example, rearrange tasks, keep being active; Bair et al., 2003; Von Korff \& Simon, 1996). Depressive symptoms include negatively biased attitudes and perceptions (Beck, 1967). This might affect the individual conceptualisation of acute and recurrent LBP (Williams, Jacka, Pasco, Dodd, \& Berk, 2006). Indeed, the course of LBP may not be actually getting worse (objective pain getting worse), but the perception is becoming more negative.

In contrast, the severity of acute LBP at medical consultation of pain did not have a direct impact on depression after three weeks. However, the pain level after three weeks was predictive for subsequent depressive symptoms. This is in line with the view that in case of tardy or missing treatment success LBP can be interpreted as a threatening and uncontrollable event, and consequently, more depressive symptoms develop. The first medical consultation is possibly linked with positive expectations, and most patients expect an improvement after the first weeks of treatment. If the LBP level, nevertheless, is high after three weeks, adequate resources to deal with the problem are not identified because the treatment was unsuccessful so far. As a result, feelings of helplessness and in turn the risk of developing depression may be increased (Williams, 1999). Similarly, Cherkin et al. (1996) found in a cohort of patients with a first visit for a current episode of LBP that unimproved LBP is related to more depressive symptoms after seven weeks of treatment, but not after three weeks of treatment. Accordingly, symptoms of depression are seldom reported at the first sign of pain, but rather after exposure to suffering, disability, and frustrations (Gatchel, 1996). Possibly, if LBP persists then patients may experience helplessness (Gatchel, 1991). To summarise, it can be postulated that LBP and depressive symptoms are generally interrelated but that their directional relation is specific depending on time under treatment. 


\section{Implications for clinical practice}

LBP is multifactorial and complex (Waddell, 1987). The findings suggest that depressive symptoms at the initial stage of LBP are involved in the maintenance of LBP severity and should not be ignored by general practitioners (Eccleston, 2001). LBP, in turn, might influence cognitions and foster the development of depressive symptoms. Pain medication at the beginning of the treatment could prevent this process (Chou \& Hoyt Huffman, 2007). Health practitioners should understand and actively evaluate the time under treatment-dependent relationship between depressive symptoms and LBP. To reduce social and health costs, depressive symptoms should be identified early (Grotle et al., 2005; Melloh et al., 2009) to prevent the development of chronic LBP (Main, Kendall, \& Hasenbring, 2012). Unsuccessful treatment after consultation should be critically evaluated by taking depressive symptoms into consideration (Kroenke et al., 2011; Rush, Polatin, \& Gatchel, 2000). To address depressive symptoms and pain, multimodal programmes including cognitive behavioural therapy (CBT) approaches appear to be promising in primary care (Middleton \& Pollard, 2005; Rolli Salathe, Elfering, \& Melloh, 2012; Williams et al., 2006). CBT includes a variety of treatments such as behaviour therapy, coping skills training, cognitive therapy, biofeedback, and relaxation (Morley, Eccleston, \& Williams, 1999). In addition, the treatment may be complemented by antidepressants (Gallagher, 2004).

\section{Strengths and limitations}

This study extended previous research findings by examining the relationship between LBP and depressive symptoms over the first weeks of treatment. The method of analysis represents an additional strength. SEM is a powerful statistical technique, which is considered to be adequate to model causal effects (Byrne, 2010). Some limitations of this study need to be addressed. First, this study includes self-reported outcomes of variables studied, which may introduce some bias. The response behaviour might be affected by mood, personality, or social desirability bias. Even though validated instruments were used, especially for depressive symptoms, a standardised psychiatric interview that concentrates on clinically relevant depressive status instead of depressive symptoms may have yielded different findings. Secondly, given the relatively high nonparticipation rate, the sample might not be representative of LBP patients in primary care. Thirdly, study attrition may have affected internal and external validity. Of the initial sample, nearly $30 \%$ were lost to follow-up. Although no significant differences were found between study participants and those who dropped out in sample characteristics, lifestyle factors, LBP history, LBP severity and depressive symptoms, some (unknown) bias may have resulted from unmeasured constructs.

\section{Conclusions and outlook}

Depressive symptoms and LBP appear to mutually reinforce each other among a population of acute or sub-acute LBP patients in primary care. There is evidence that the direction of the relationship changes over time. At the time LBP patients seek care, depressive symptoms were a risk factor for elevated pain after three weeks. This, in turn, led to more severe depressive symptoms at six weeks. A vicious circle should be avoided by early treatment of depressive symptoms. Health practitioners should screen for depressive symptoms in order to avoid persisting LBP. 


\section{References}

Andersson, G.B. (1999). Epidemiological features of chronic low-back pain. Lancet, 354(9178), 581-585. doi: 10.1016/S0140-6736(99)01312-4

Angst, F., Verra, M.L., Lehmann, S., Aeschlimann, A., \& Angst, J. (2008). Refined insights into the pain-depression association in chronic pain patients. Clinical Journal of Pain, 24, 808816. doi: 10.1097/AJP.0b013e31817bcc5f

Bair, M.J., Robinson, R.L., Katon, W., \& Kroenke, K. (2003). Depression and pain comorbidity: A literature review. Archives of Internal Medicine, 163, 2433-2445. doi: 10.1001/archinte. 163.20 .2433

Barrett, P.W. (2007). Structural equation modelling: Adjudging model fit. Personality and Individual Differences, 42, 815-824. doi: 10.1016/j.paid.2006.09.018

Beck, A.T. (1967). Depression: Clinical, experimental, and theoretical aspects. New York, NY: Harper \& Row.

Burckhardt, C.S., \& Bjelle, A. (1994). A Swedish version of the short-Form McGill Pain Questionnaire. Scandinavian Journal of Rheumatology, 23, 77-81.

Byrne, B.M. (2010). Structural equation modeling with Amos: Basic concepts, applications, and programming (2nd ed.). New York, NY: Taylor and Francis.

Cherkin, D.C., Deyo, R.A., Street, J.H., \& Barlow, W. (1996). Predicting poor outcomes for back pain seen in primary care using patients' own criteria. Spine, 21, 2900-2907.

Chou, R., \& Hoyt Huffman, L. (2007). Medications for acute and chronic low back pain: A review of the evidence for an American pain society/American college of physicians clinical practice guideline. Annals of Internal Medicine, 147, 505-514.

Cole, D.A., \& Maxwell, S.E. (2003). Testing mediational models with longitudinal data: Questions and tips in the use of structural equation modeling. Journal of Abnormal Psychology, 112, 558-577. doi: 10.1037/0021-843X.112.4.558

Currie, S.R., \& Wang, J. (2004). Chronic back pain and major depression in the general Canadian population. Pain, 107, 54-60. doi: 10.1016/j.pain.2003.09.015

Dragan, A., \& Akhtar-Danesh, N. (2007). Relation between body mass index and depression: A structural equation modeling approach. BMC Medical Research Methodology, 7, 17. doi: $10.1186 / 1471-2288-7-17$

Eccleston, C. (2001). Role of psychology in pain management. British Journal of Anaesthesia, 87, 144-152. doi: 10.1093/bja/87.1.144

Elfering, A., \& Mannion, A.F. (2008). Epidemiology and risk factors of spinal disorders. In N. Boos \& M. Aebi (Eds.), Spinal disorders - Fundamentals of diagnosis and treatment (pp. 153-173). Berlin: Springer.

Elfering, A., Mannion, A.F., Jacobshagen, N., Tamcan, O., \& Müller, U. (2009). Beliefs about back pain predict the recovery rate over 52 consecutive weeks. Scandinavian Journal of Work, Environment and Health, 35, 437-445. doi: 10.5271/sjweh.1360

Fishbain, D.A., Cutler, R., Rosomoff, H.L., \& Rosomoff, R.S. (1997). Chronic pain-associated depression: Antecedent or consequence of chronic pain? A review Clinical Journal of Pain, $13,116-137$.

Gallagher, R.M. (2004). Biopsychosocial pain medicine and mind-brain-body science. Physical Medicined Rehabilitation Clinics of North America, 15, 855-882. doi: 10.1016/j. pmr.2004.04.002

Gatchel, R.J. (1991). Early development of physical and mental deconditioning in painful spinal disorders. In T.G. Mayer, V. Mooney, \& R.J. Gatchel (Eds.), Contemporary conservative care for painful spinal disorders. New York, NY: Guilford Press.

Gatchel, R.J. (1996). Psychological disorders and chronic pain: Cause and effect relationships. In R.J. Gatchel \& D.C. Turk (Eds.), Psychological approaches to pain management: A practitioner's handbook. New York, NY: Guilford Press.

Georgoudis, G., Watson, P.J., \& Oldham, J.A. (2000). The development and validation of a Greek version of the short-Form McGill Pain Questionnaire. European Journal of Pain, 4, 275-281. doi: 10.1053/eujp. 2000.0186.

Grotle, M., Brox, J.I., Veierod, M.B., Glomsrod, B., Lonn, J.H., \& Vollestad, N.K. (2005). Clinical course and prognostic factors in acute low back pain: Patients consulting primary care for the first time. Spine, 30, 976-982. doi: 00007632-200504150-00021 
Hirschfeld, R.M.A., \& Weissman, M.M. (2002). Risk factors for major depression and bipolar disorder. In K.L. Davis, J.T. Charney, J.T. Coyle, \& C. Nemeroff (Eds.), Neurospychopharmacology (pp. 1017-1025). Philadelphia, PA: Lippincott Williams \& Wilkins.

Hurwitz, E.L., Morgenstern, H., \& Yu, F. (2003). Cross-sectional and longitudinal associations of low-back pain and related disability with psychological distress among patients enrolled in the UCLA low-back pain study. Journal of Clinical Epidemiology, 56, 463-471. doi: 10.1016/S0895-4356(03)00010-6

Kroenke, K., Wu, J., Bair, M.J., Krebs, E.E., Damush, T.M., \& Tu, W. (2011). Reciprocal relationship between pain and depression: A 12-month longitudinal analysis in primary care. The Journal of Pain, 12, 964-973. doi: 10.1016/j.jpain.2011.03.003

Linton, S.J., Nicholas, M.K., MacDonald, S., Boersma, K., Bergbom, S., Maher, C., \& Refshauge, K. (2011). The role of depression and catastrophizing in musculoskeletal pain. European Journal of Pain, 15, 416-422. doi: 10.1016/j.ejpain.2010.08.009

Magni, G., Moreschi, C., Rigatti-Luchini, S., \& Merskey, H. (1994). Prospective study on the relationship between depressive symptoms and chronic musculoskeletal pain. Pain, 56, 289297. doi: 10.1016/0304-3959(94)90167-8

Main, C.J., Kendall, N.A.S., \& Hasenbring, M.I. (2012). Screening of psychosocial risk factors (yellow flags) for chronic back pain and disability. In M.I. Hasenbring, A.C. Rusu, \& D.C. Turk (Eds.), From acute to chronic back pain. Risk factors, mechanisms, and clinical implications (pp. 203-230). New York, NY: Oxford University Press.

Main, C.J., Wood, P.L., Hollis, S., Spanswick, C.C., \& Waddell, G. (1992). The distress and risk assessment method. A simple patient classification to identify distress and evaluate the risk of poor outcome. Spine, 17, 42-52.

Melloh, M., Aebli, N., Elfering, A., Roder, C., Zweig, T., Barz, T., ... Theis, J.C. (2008). Development of a screening tool predicting the transition from acute to chronic low back pain for patients in a GP setting: Protocol of a multinational prospective cohort study. BMC Musculoskeletal Disorders, 9, 167-. doi: 10.1186/1471-2474-9-167

Melloh, M., Elfering, A., Egli Presland, C., Roeder, C., Barz, T., Rolli Salathe, C., ... Theis, J.C. (2009). Identification of prognostic factors for chronicity in patients with low back pain: A review of screening instruments. International Orthopaedics, 33, 301-313. doi: 10.1007/ s00264-008-0707-8

Melloh, M., Elfering, A., Egli Presland, C., Roder, C., Hendrick, P., Darlow, B., \& Theis, J.C. (2011). Predicting the transition from acute to persistent low back pain. Occupational Medicine, 61, 127-131. doi: 10.1093/occmed/kqq194

Melloh, M., Elfering, A., Chapple, C.M., Kaser, A., Rolli Salathe, C., Barz, T., \& Theis, J.C. (2012). Prognostic occupational factors for persistent low back pain in primary care. International Archives of Occupational and Environmental Health-. doi: 10.1007/s00420012-0761-9

Melloh, M., Elfering, A., Salathe, C.R., Kaser, A., Barz, T., Roder, C., \& Theis, J.C. (2012). Predictors of sickness absence in patients with a new episode of low back pain in primary care. Industrial Health, 50, 288-298. doi: 10.2486/indhealth.MS1335

Melzack, R. (1987). The short-form McGill pain questionnaire. Pain, 30, 191-197.

Melzack, R., \& Katz, J. (2006). Pain assessment in adult patients. In S. McMahon (Ed.), Textbook of pain (pp. 191-315). Edinburgh: Churchill Livingstone.

Menezes Costa, L.C., Maher, C.G., Hancock, M.J., McAuley, J.H., Herbert, R.D., \& Costa, L.O.P. (2012). The prognosis of acute and persistent low-back pain: A meta-analysis. Canadian Medical Association Journal, 184, E613-E624. doi: 10.1503/cmaj.111271

Middleton, P., \& Pollard, H. (2005). Are chronic low back pain outcomes improved with co-management of concurrent depression? Chiropractice and Osteopathy, 13, 8. doi: 10.1186/1746-1340-13-8.

Morley, S., Eccleston, C., \& Williams, A. (1999). Systematic review and meta-analysis of randomized controlled trials of cognitive behaviour therapy and behaviour therapy for chronic pain in adults, excluding headache. Pain, 80, 1-13.

Pengel, L.H., Herbert, R.D., Maher, C.G., \& Refshauge, K.M. (2003). Acute low back pain: Systematic review of its prognosis. British Medical Journal, 327, 323. doi: 10.1136/ bmj.327.7410.323 
Pincus, T., Santos, R., Breen, A., Burton, A.K., \& Underwood, M. (2008). A review and proposal for a core set of factors for prospective cohorts in low back pain: A consensus statement. Arthritis \& Rheumathism, 59, 14-24. doi: 10.1002/art.23251

Pincus, T., \& Williams, A. (1999). Models and measurements of depression in chronic pain. Journal of Psychosomatic Research, 47, 211-219. doi: 10.1016/S0022-3999(99)00045-8

Polatin, P.B., Kinney, R.K., Gatchel, R.J., Lillo, E., \& Mayer, T.G. (1993). Psychiatric illness and chronic low-back pain. The mind and the spine - which goes first? Spine, 18, 66-71.

Potter, R.G., \& Jones, J.M. (1992). The evolution of chronic pain among patients with musculoskeletal problems: A pilot study in primary care. British Journal of General Practice, 42, 462-464.

Rolli Salathe, C., Elfering, A., \& Melloh, M. (2012). Efficacy, utility and cost-effectiveness of multidisciplinary treatment for chronic low back pain. Schmerz, 26, 131-149. doi: 10.1007/ s00482-012-1148-2

Rush, A.J., Polatin, P., \& Gatchel, R.J. (2000). Depression and chronic low back pain: Establishing priorities in treatment. Spine, 25, 2566-2571. doi: 10.1097/00007632-200010150-00004

Seligman, M.E.P. (1975). Helplessness. On depression, development and death. San Francisco, CA: Freeman.

Shaw, W.S., Means-Christensen, A.J., Slater, M.A., Webster, J.S., Patterson, T.L., Grant, I., \& Atkinson, J.H. (2010). Psychiatric disorders and risk of transition to chronicity in men with first onset low back pain. Pain Medicine, 11, 1391-1400. doi: 10.1111/j.15264637.2010.00934.x

Von Korff, M., Ormel, J., Katon, W., \& Lin, E.H. (1992). Disability and depression among high utilizers of health care. A longitudinal analysis. Archives of General Psychiatry, 49, 91-100.

Von Korff, M., \& Simon, G. (1996). The relationship between pain and depression. British Journal of Psychiatry Supplement, 30, 101-108.

Waddell, G. (1987). 1987 Volvo award in clinical sciences. A new clinical model for the treatment of low-back pain. Spine, 12, 632-644.

Williams, D.A. (1999). Acute pain. In R.J. Gatchel \& D.C. Turk (Eds.), Psychosocial factors in pain: Evolutions and revolutions (pp. 151-163). New York, NY: Guilford Press.

Williams, L.J., Jacka, F.N., Pasco, J.A., Dodd, S., \& Berk, M. (2006). Depression and pain: An overview. Acta Neuropsychiatrica, 18, 79-87. doi: 10.1111/j.1601-5215.2006.00130.x

WMA. (2008). Declaration of Helsinki - ethical principles for medical research involving human Subjects; 59th WMA General Assembly, Seoul, Korea, October 2008.

Young Casey, C., Greenberg, M.A., Nicassio, P.M., Harpin, R.E., \& Hubbard, D. (2008). Transition from acute to chronic pain and disability: A model including cognitive, affective, and trauma factors. Pain, 134, 69-79. doi: 10.1016/j.pain.2007.03.032

Zung, W.W. (1965). A self-rating depression scale. Archive of General Psychiatry, 12, 63-70. 